\title{
Trends on Science Education Research Topics in Education Journals
}

\author{
Konstantinos Karampelas ${ }^{1 *}$ \\ ${ }^{1}$ Pedagogic Department of Elementary Education, University of the Aegean, Rhodes, GREECE \\ *Corresponding author: kkarampelas@aegean.gr
}

Received: 15 Nov. $2020 \bullet$ Revised: 11 Dec. $2020 \bullet$ Accepted: 21 Dec. 2020

Citation: Karampelas, K. (2021). Trends on Science Education Research Topics in Education Journals. European Journal of Science and Mathematics Education, 9(1), 1-12. https://doi.org/10.30935/scimath/9556

\begin{abstract}
:
This research aims to identify the trends in the field of science education, during the last decade. Generally, these trends are compatible with the developments in the field of science education, which mostly emphasize teaching practices and methods. Similar projects have been carried out during previous decades, focusing on research articles published in journals specializing in science education. Instead, the emphasis of this study is on journals that focus generally on the field of education research. The findings show that there are articles in these journals addressing science education and overall, they reflect the developments in the research of the particular field.

Keywords: research topics, journals, science
\end{abstract}

\section{INTRODUCTION}

The scope of this article is to highlight the topics with more frequent articles relating to science education published in journals concerned with education research, generally. This topic has not been researched thoroughly so far (Chang et al., 2009; Lin et al., 2018; Martin et al., 2012). Researchers publish their journal articles as part of their effort to disseminate their work, the study they author to contribute to the development of their field. Dissemination of articles is relevant to the trends in this field. By reviewing the topics of articles, it is possible to discover what researchers consider important or feasible in their works (Ary et al., 2010; Cohen, Manion, \& Morrison, 2011; Pring, 2000).

Science education is a topic of central interest to education researchers. Its focus is to identify the most appropriate conditions that schools, education systems, institutions and the society generally need to satisfy, to promote scientific literacy. This is important so that learners will be able to understand, approach critically the progress of science and technology and contribute to it (OECD, 2000, 2006, 2019).

To achieve its objective, this research will focus on certain areas, viz., issues around education research and implementation, science education, science education article topics, etc. as they have been researched.

\section{EDUCATION RESEARCH}

The overall aim of education research is to identify the truth in processes, phenomena and concepts linked to the complex field of education. This search for truth is always influenced by the social context in which research is conducted, since education belongs to the so-called area of social sciences. To appreciate the way research develops, it is necessary to understand research paradigms, data collection topics and dissemination. 


\section{The Research Paradigms}

The study of how education research develops and should be carried out dates back many decades. This study of the truth that can lead to applicable and feasible education knowledge has been dominated mostly by two basic paradigms--the positivistic and non-positivistic. The former relies on the idea that the researcher is an observer of an educational reality and aims to analyze and conceive it. This effort is undertaken according to established and accepted norms and models. Dewey (1938) introduced the scientific method of carrying out education research, which consists of five basic stages. The first stage is the precise identification of the problem or the question. The second is the formulation of a hypothesis, which is a statement, the validity of which is tested as a possible solution to the problem or answer to the question. The third is the planning and organizing of data which includes collecting and analyzing them, according to accepted patterns or practices. The fourth is the formulation of conclusions, which can serve as or lead to explanations and new knowledge. The fifth step is the verification, moderation, or rejection of the initially stated hypothesis, which is examined in different and specific contexts (Best \& Kahn, 2006; Cohen et al., 2011).

Non-positivism, on the other hand, relies on the idea that the researcher carries certain values, beliefs and characteristics that will have to be taken into thorough consideration. In this approach, the individual gets more credit, attention, and value, whereas in the positivist approach, credit is attributed to the social context instead. This point of view leads to other differences. Perhaps the basic distinction between positivists and non-positivists is that while the former tend to support an objective reality and knowledge, the latter treat knowledge and reality as more subjective, highly dependent on a number of parameters, primarily the prism of the observer-researcher. Another point is that the non-positivist research does not totally, or at least not by default, rely on the scientific method, as the main target is to get an in-depth understanding of the behavior the researched subjects demonstrate. In fact, in most cases of non-positivism, there is no stated hypothesis. Instead, there is a well justified assertion, which is derived from research findings. This assertion or thesis is tested as well, as a means of evaluating a theory, in different contexts or under new conditions. It is these characteristics that have generated the need for a paradigm, contrary to the positivist, which has been accepted but also criticized for seeing a rather absolute and determined view of human nature. This trend was found particularly useful in the fields of social science, such as psychology, sociology and education, where the behavior of humans was thought to be better dealt with as a whole, complex system (Ary, Jacob, Sorensen, \& Ravazieh, 2010; Cohen et al., 2011).

This bipolarity in paradigms has led to the development of two major approaches to education research. The first is quantitative research, based on the positivist paradigm. Quantitative researchers aim usually to describe educational reality by uncovering or making precise relationships between concepts, phenomena, states, or conditions. This involves distinguishing cause and effect. The design for such research is expected probably to be rigid and developed prior to the implementation of the research study, as it must follow the scientific method strictly. This way, it is mostly deductive. It involves preselected instruments that are approved as accurate and able to provide valuable outcomes. These instruments are usually related to statistics and distributions that are applied usually to analyze large samples of numeric data.

The second is qualitative research, based on the non-positivist paradigm. Qualitative researchers aim usually to describe educational reality by studying phenomena in depth, in as much rich detail as possible. This requires a design, which however is more flexible compared to quantitative research, as it can be elaborated and updated as research progresses. This way, it is mostly inductive, as it aims to generate a new theory or evaluate an accepted one in a different context or through a new prism. The data collection is done primarily in smaller samples and uses analytical methods that rely on narration and interpretation of codes and categories (Ary et al., 2010). 
Selecting the appropriate approach depends each time on the topic and the focus of the research. Although in the past these approaches were considered to be adversarial, over the last decades, most researchers tend to consider them as complementary. In fact, it is accepted that in most cases, no research can be exclusively quantitative or qualitative. For this reason, there is a lot of focus currently on the emerging paradigm of mixed methods methodology (Ary et al., 2010; Pring, 2000).

\section{Data Collection}

Selecting the data is certainly a crucial part of the research and calls for careful attention to every stage of the research from the initial part of planning, to the final parts of dissemination and revision. There are some key issues to be considered. A major issue is accessibility to the data. In other words, researchers should identify as early as possible who or which source could provide them the appropriate information and at what cost or requirement. It is important to know how easy or challenging it would be to get the data and through what procedures. For example, when carrying out research in schools, it might be necessary to get formal permission from different groups of people, such as teachers, parents, or local authorities. Apart from that, there should be emphasis on ethical considerations, so that participants will not be exposed to or put at risk.

Other key issues are reliability and validity. The former refers to ensuring that the data obtained will be re-obtained, if collected by the same process in the same way. For example, if using a software in science sessions leads to better teaching, there should be an assurance that if the sessions use this software again, the same outcomes would emerge. The latter is more complex. It has to do with having accurate data that will lead to useful conclusions that can be generalized and used by other researchers, experts, or scientists (Bell, 2005; Cohen et al., 2011).

\section{Research Dissemination}

Since this research focuses on research articles, which serve the purpose of research dissemination, it is important to list the basic points relating to this topic.

As Bywood et al. (2008) claim, the scope of dissemination of research is to promote reform and change. Thanks to the dissemination of findings, it is possible to promote a shift in the organizational context. For example, by contributing to the announcement and acquisition of the education research findings, it is possible to assist in the adoption of new focus or approaches in schools, educational institutes, and agencies.

This shift can be identified at different levels. At the intrapersonal level, research can have an impact on an individual's motivation, action, values, behavior, perceptions and intentions (Bywood et al., 2008; Pring, 2000). In teachers, this might be relevant to the desired 'metanoia', or shift of mind, that Senge (1990, p. 5) held to be necessary for development to happen. At an interpersonal level, dissemination can cause reform and re-arrangement of relationships. Teachers, for instance, might be motivated by research to reconsider their expectations, roles, and relationships vis-à-vis colleagues, students, parents, policy makers and other groups of people. Finally, at the organizational level, dissemination can cause identification and overcoming of challenges, as well as opportunities for professional development (Bywood et al., 2008; Kelly, 2004).

All the above can lead to complete re-arrangement of the educational system and shift in the general school climate or school culture, which are necessary if sustainable and systemic reform as well as school improvement are to be achieved (Fullan, 2007).

Bywood et al. (2008), while describing the phenomenon of dissemination, identified stage models which explain its impact on society, along with its contribution to research. Their actual idea is based on the notion that the impact can be observed in behavioral change at individual, organizational or social level. 
In other words, as research is being disseminated, it should make individuals and groups behave differently and demonstrate that they apply the findings of the research, wherever applicable. Change though is a complicated and on-going process. As Fullan (2007) claims, it is complicated to approach change; however it is generally accepted as a cyclical process. It starts with the identification of a problem, followed by the investigative stage, where research has an important role and then the implementation, where research is applied and evaluated. Thanks to this process, improvement and development are achieved by changing behavior at all levels. This however serves afterwards as an identification of a new challenge, which leads to new change cycle. Research generates new research as it leads to new queries and identification of new issues that call for improvement (Fullan, 2007; Pring, 2000).

The topic of this research is therefore linked to this point, as by examining how research in science education develops, it is possible to conclude which topics are investigated in this field. This itself can give insights into worthwhile issues and as a result of the behavior of individuals, groups, and organizations towards them (Bywood et al., 2008; Kelly, 2004).

\section{RESEARCH IN SCIENCE EDUCATION}

Research in science education aims overall to examine and identify the appropriate ways to help learners become scientifically literate, in educational organizations, systems, contexts, or institutions. Besides that, it aims to provide insights into the progress achieved in that direction. It is important to examine the term of science literacy and then identify which topics relevant to this are more frequently selected by researchers for investigation and publication (OECD, 2006).

\section{Science Literacy}

The concept of scientific literacy is dynamic and there have been numerous efforts to provide definitions thereof. Indicatively, OECD (2000) has defined it thus:

The capacity to use scientific knowledge, to identify questions and to draw evidence-based conclusions in order to understand and help make decisions about the natural world and the changes made to it through human activity (p. 10).

Over the years, though, this definition has been reviewed, revised, refined, and elaborated upon. In this elaboration, three basic aspects of scientific literacy have been clarified. A scientifically literate person should have the ability to explain scientific phenomena, design and evaluate tasks of scientific inquiry and interpret data and evidence. The first ability is related to content knowledge, which focuses on topics of science and technology. A scientifically literate person can define or describe concepts, phenomena, and processes. The other two abilities relate to understanding how the accepted scientific knowledge is approached, defined, and investigated. These are linked more to skills and attitudes than content knowledge and relate to processes. They address actions, conditions, and criteria that scientists use and go through to form new knowledge. They are linked to epistemic knowledge as well, which includes knowing about the nature of science, understanding what science and scientific knowledge consist of and where their importance lies. Thanks to this approach, learners are not restricted to memorizing individual information about concepts and phenomena and can, instead, understand better what science really is and what it has contributed to their lives (OECD, 2019).

The development of scientific literacy and its education have been found to be better approached through the development of eight practices. These address the desired outcomes that school science should focus on and learners are expected to develop: to ask questions in science and define problems in engineering, to develop models and use them, to plan and implement investigations, to analyze and interpret data, to use mathematical and computational thinking, to construct explanations in science 
and design solutions in engineering topics, to engage in argument from evidence and discourse and to obtain, evaluate and communicate information.

All these practices are expected to be developed by all learners, regardless of background or academic performance. Their promotion is interwoven. Even though each practice can be studied and planned individually, all of them should be promoted together parallelly, as they represent significant dimensions of science literacy. They depend on appropriate skills, as well as hands-on activities. These are suggested to be based on inquiry-based activities and tasks, where each learner will work cooperatively on topics inspired by everyday life. It is recommended that learners and students should participate actively in sessions, if these practices are to be achieved (NGSS, 2013).

In short, scientific literacy has moved over the last decade beyond scientific knowledge and has focused on other aspects of science, such as its epistemology and process. Certainly, knowledge itself is still considered important. It is concluded that science teaching will become more efficient if learners understand basic issues about what science or scientific knowledge actually is and how it develops. This approach helps the learners acquire a better understanding of science and scientific knowledge and implement them in their everyday life (OECD, 2019). Policy, along with research on science teaching, is expected to emphasize these issues. Only under this condition can the educational and scientific community justify that at the level of implementation, scientific literacy is indeed the ultimate goal of science teaching (OECD, 2019; Pring, 2000).

In sum, research in science education examines how schools promote the ultimate goal of science teaching, which is the development of scientific literacy. There is therefore a strong inter-relation between research and the concept of scientific literacy. This concept though is continuously examined and revised, in terms of content. This research aims to provide insights into the impact of changes in the content of scientific literacy on the trends of science teaching research. In other words, it tries to examine whether these trends actually reflect any content changes. In doing so, it is important to see the topics that research in science education focuses upon, overall (Cohen et al., 2007; Martin et al., 2012; Nyberg, Koerber, \& Osterhausm 2020; OECD, 2019; Pring, 2000).

\section{Topics in Science Education Research}

In the 1980s, Penick and Yager (1986) listed four categories of topics that research in science teaching focuses on. The first was the engagement of experts or science practitioners or professionals in school functions. The second related to supporting the science programs of schools with various resources. The third was the cooperation of the school with centers, laboratories, and organizations associated with scientific research and work. Finally, the fourth concerned dealing with the wider environment as a science laboratory, where science processes take place and can therefore be studied and understood. These four categories overall stress that school science teaching and schools generally should be treated in a context of interaction with the wider society.

Later, during the 1990s, Gil-Perez (1996) posited that science teaching research had moved into identifying misconceptions in learners' understanding of phenomena and concepts. This was done in the context of introducing new paradigms such as constructivism in science teaching. This trend was associated with all the elements and conditions that support these paradigms and their rationale. For example, there was research aimed at pointing out the false ideas learners have about scientific phenomena and what activities can be used to eliminate them. Besides that, there was research on the need to actively involve learners in the instruction and not treat them as passive knowledge receivers. Moreover, there was emphasis on the importance of promoting appropriate skills and attitudes during the session, not restricted to knowledge (Driver et al., 1996). 
Chang, Chang and Tseng (2009), along with Lin et al. (2018), attempted to draw a broader picture of science education research as it has developed and its dimensions. The authors grouped the topics that researchers in science education have focused on, over the last decades.

Teacher education and the appropriate professional development orientation is one topic, which includes mostly preparing teachers for instructions and evaluating their ideas, challenges, and performance.

Another topic is teaching, which includes evaluating the effectiveness of practices and learning models and approaches, usually in comparison with others previously established.

Learning concepts and phenomena is very popular, as well and it focuses on content knowledge such as plants, animals, energy, astronomy and other parts of the curriculum, which are approached individually (Martin et al., 2012).

Learning and rejecting misconceptions have attracted attention too, as these were foundational points of the constructivist approach, recognized as main issues for teachers to deal with (Driver et al., 1996).

Goals, policy, and the curriculum with regards to science, are also a topic that has stimulated the interest of researchers. This usually involves examining parts and points of the curriculum with regard to teachers' views and implementation of science teaching.

There are also articles and projects examining whether social topics influence the teaching of science. For example, there is research whether factors such as religion, gender or culture have an impact on the performance of learners in science (Martin et al., 2012).

Another topic which has attracted researchers' attention is the concept of science itself, its characteristics, identity and dimensions, along with its educational implementation. For instance, there is interest in trying to include the philosophy, nature, or history of science. There are researchers who consider this an effort to help learners conceive a deeper idea of science and become more scientifically literate.

Emphasis is also placed on using Information and Communication Technology applications in science subjects. These applications could be various softwares or hardwares. There could be general or particular images, documents, text-editing documents, spreadsheets, slides, data-loggers, websites, videos or even visual representations and simulations of natural phenomena, which are considered by researchers as worth using in instruction, generally or specifically in individual sessions or concepts (Martin et al., 2012).

Finally, there is research on the informal learning of science. This involves opportunities to learn science in contexts outside the formal curriculum structure. Such learning might be achieved in places such as parks, natural history museums, zoo, science laboratories or other relevant places of interest.

To sum up, the main research themes that science education emphasizes are: teacher education, teaching and instruction, conceptional learning, concept learning, goals, policy and curriculum of science, cultural, social and gender issues in science, philosophy, history and nature of science, education technology in science and informal learning. These topics sometimes overlap, and sometimes they are interwoven and inter-related (Martin et al., 2012). Individual papers and research projects might emphasize one of the above. However, by considering how all of them interact, it is possible to draw an accurate image of the whole progress of science teaching research (Bodner \& Elmas, 2020; Chang et al., 2009; Lin et al., 2019; McDermott, 2013). 
As Pring (2000) indicates, the trends around research and popularity of research topics are certainly affected by many factors, which might not be totally attributed to education, but to developments in other fields of social studies which influence teaching and schools generally. Chang et al. (2009) identified that during 1990-2010, a large number of journal articles on science education focused on changing science conceptions, perhaps due to the significant interest in constructivism then. This teaching approach was based on the finding that learners arrive in school, having formed misconceptions around phenomena and concepts, which have to be negotiated and rejected during instruction (Driver et al., 1996).

Besides, there has been increased research around professional development, cultural issues of science, modeling, and analogies (Chang et al., 2009). This can also be linked with the general interest in these topics, which was boosted by the general trends around science or education (Martin et al., 2011).

According to Lin et al. (2019), science teaching with the help of ICT attracted great interest during 19902010, only to decline during the following years. A possible explanation is the interest in teaching practices, which was considered by teachers and researchers to deserve certain priority. However, education technology has remained a point of interest among researchers, especially since the emergence of STEM education.

\section{Science Education Research Trends in Journals}

Several projects have been undertaken to examine the focus of research published in science education journals, over the last decades. These projects paid attention to various parameters. The basic ones were the types of research carried out as well as the topics. These parameters were benchmarked with general trends in science education, pedagogy, and social science (Martin et al., 2012).

Chang et al. (2009), along with Lin et al. (2018), concluded that from year 2000, a rather large number of such articles is mostly qualitative and empirical. Quantitative research is not that common, while mixed methods have been adopted in several cases. They focus much on teaching practices, as implemented in the classroom; for example, they examine the implementation of a specific innovative practice in a science unit, as it was attempted in a specific context, regarding its effectiveness and challenges. This trend was attributed to the rising interest in these fields, in combination with the saturation of others that used to be rather popular in the past, such as changes in knowledge conception, gender and social topics in science. Another topic they examined was innovative units, such as the nature of science, caused perhaps by greater social stimuli calling for new qualities that schools needed to promote. For instance, the need for scientific literacy for competent citizens has probably pushed research in that direction. These trends called for citizens who can implement the knowledge along with the processes of science, including discourse, inquiry and argumentation in real-life situations, in order to make decisions and solve problems.

These projects paid attention to journals that emphasized science education. Similar research in other areas of greater general interest in the field of education appears limited. In other words, there seems to be insufficient research on the trends on science education articles in journals catering generally to education research and studies. The rationale of such research is that it can give insights into the importance of and general attention on science education, within the broader field of education.

Chang et al. (2009) as well as Lin et al. (2018) concluded that the majority of articles in their research, focused on the period 2000-2015, emphasized conceptual change, misconceptions and learning context. Lin et al. (2018) pointed out that this focus appeared to decline from 2010, perhaps attributable to the domination of the focus on knowledge and the paradigm of constructivism. These trends prevailed in the recent past in the field of science education and science teaching (Driver et al., 1996; Martin et al., 
2012; OECD, 2000). They are also associated with the OECD (2000) definition of and approach to scientific literacy. It is worth examining whether the shifts in the concepts were accompanied by shifts in research focus as well (Bywood et al., 2008; Fullan, 2007).

\section{THE RESEARCH}

In the aforesaid background, a research project was designed to identify the number of articles in educational journals of rather general orientation and interest, focused on science teaching and science education. The importance of this research lies in its ability to provide insights into the main orientations of science research through the prism of a general pedagogical context, which has not been thoroughly examined until recently. This is therefore a topic which presents significant scope for further investigation and interest (Bell, 2001; Pring, 2000). Researchers and organizations who approach education at a general level have stressed the importance of science, and consequently that of science teaching and science education research (OECD, 2000, 2018).

Over the last decades, science education research as disseminated, has focused on various topics such as teacher education, teaching practices, learning concepts, conceptual change, goals, policy and curriculum, social and cultural dimensions of science teaching, Nature, philosophy and history of science, ICT, STEAM and science teaching, informal learning in science (Chang et al., 2009; Lin et al., 2018), etc. Overall, it is noted that science education research follows the currents of the general social and educational research (Gil-Perez, 1996; Martin et al., 2012; Penick \& Yager, 1986)

Within the scope of this research, articles of four different educational journals have been examined, consisting of articles of all issues from 2010 to 2020. The names of the journals have been kept confidential due to ethical considerations (Cohen et al., 2011; Pring, 2000). The number of all the articles has been noted, along with a record of all the articles in the field of science teaching and science education. As soon as these articles were traced, the topic they focused on was identified, based on the classification of science education topics (Chang et al., 2009; Lin et al., 2018).

It was also noted whether the research paradigm implemented was quantitative, qualitative, or mixed.

By examining these fields, it is possible to ascertain whether there has been a change in trends during the decade of 2010-2020 vis-à-vis earlier years, as found by researchers (Chang et al., 2009; Lin et al., 2018; Pring, 2000). It is also possible to identify whether there is compatibility between the development of research and the development of approach to scientific literacy; in other words, whether it is possible to see what researchers believe to be the main topics in science teaching and which they consider worth investigating and improving (Gil-Perez, 1996; Martin et al., 2012; Penick \& Yager, 1986). This can identify whether there is any shift in the thinking and ideas relating to science education at the level of the behavior of individuals, groups, or organizations and how it is perceived.

\section{FINDINGS}

As it can be seen in Table 1, in the issues examined, there were generally 6504 articles. Among them, 400 focused on science education. It was observed during data collection that in each issue, there were fifteen articles on an average. Among them, there were at least one or two about science education, which proves that there is indeed interest in this field. 
Table 1. The following is the topic-wise break up of articles

\begin{tabular}{lc}
\hline Total Articles & 6504 \\
\hline Science Education & 400 \\
Teacher education \& Professional Development & 25 \\
Teaching Practices & 168 \\
Learning Concepts & 128 \\
Conceptions and Misconceptions & 30 \\
Curriculum and Policy & 45 \\
Social, Gender, Culture & 5 \\
Science Philosophy, History, NOS & 15 \\
Science and ICT & 40 \\
Informal Learning of Science & 10 \\
Qualitative & 256 \\
Quantitative & 72 \\
Mixed & 24 \\
\hline
\end{tabular}

There are two dominant fields in science education research, across the articles examined, of which a large number relate to teaching practices and the techniques that the teachers use in the classroom, their implementation and effectiveness. Additional topics are learning concepts and the way they are approached by educators and learners.

The rest of the fields do not seem to emerge in similar high frequency, as few articles address them. A small number of articles deal with teacher education, misconceptions, curriculum and ICT. The number of articles on social issues of science, nature of science, or informal learning is even less.

The emphasis on teaching practices can be attributed to the promotion of next Generation Science Standards (NGSS, 2013). This new approach to science teaching highlights what teachers do in the classroom and the practices they select to implement, providing insights into how effectively teachers implement the practices in the classroom and in their work. By viewing the practices, it is possible to see whether teachers actually implement inquiry-based science activities and engage learners in them. It is also possible to ascertain whether they tend to develop models and whether they emphasize the need to ask questions. These are examples of practices associated with the standards. Therefore, the introduction of the theory of Standards generated interest in these practices. This finding generally proves that the general theory on science education has an impact on the trends in research journals (Cohen et al., 2007; OECD, 2019; Pring, 2000).

A significant finding is that there is a small number of articles dealing with misconceptions. This might be attributed to the receding importance of the paradigm of constructivism, which, despite its continued existence, lacks the dominant presence that it enjoyed in the previous decades (Driver et al., 1996). This might be linked to the development of the terms of scientific literacy in various ways. Initially, in the absence of a monopoly in the knowledge dimension, there was less focus on the development of false ideas around scientific knowledge, even though learning concepts are not neglected. It might also be the case that since the ideas were well identified in the previous decades, researchers decided to focus more on identifying practices on how to reject them. In that sense, misconceptions are approached as an independent field, but as part of others such as the teaching practices and learning concepts, which are considerably more frequent. This can justify the tendency of research leading not only to findings, but also to new questions. Since there are findings on what the false ideas are, the question that arises is how to teach to reject them in practice (Bell, 2001; Fullan, 2007; Pring, 2000). 
Lastly, there still seems to be preference for qualitative methodology, even though there is a major essential part of articles that rely on quantitative or mixed method. This might relate to the previously observed trends. For instance, since there is concern on teaching practices, researchers prefer to carry out an empirical research that takes place in a classroom in the form of an action research case. The same would apply in cases where researchers examine approaches to learning concepts or implement science teaching with the help of a tool or software. Generally, qualitative methodology is preferred in these cases. Quantitative research might apply more to studies that focus on the social aspects of science education, such as gender issues or teaching immigrants. These topics, however, are observed in rather small numbers. This finding is compatible with the ones of previous studies (Chang et al., 2009; Lin et al., 2018). The preference for qualitative research in the classroom might have to do with the accessibility of data as well, since obtaining information from large samples of population for quantitative research might not always be an easy option for researchers (Ary et al., 2010; Cohen et al., 2011; Pring, 2000).

Overall, it is revealed that there is influence from the development of scientific literacy in the areas and topics under study (OECD, 2019). The most popular fields of research in science education seemed to be the teaching practices and learning concepts, which focus on what exactly the teacher does inside the classroom and how effective and feasible it is. This trend seems to continue from the past decades (Chang et al., 2009; Lin et al., 2018; Martin et al., 2012). The articles around misconceptions and children's ideas in science do exist, but are fewer than in the past. This probably happens since in previous decades, the paradigm of constructivism had captured the attention of researchers, which however has declined (Chang et al., 2009; Driver et al., 1996). Apart from that, there is a small number of articles concerning aspects such as teacher education, ICT, social issues like the nature of science or other factors (as for example gender or social background). Finally, the dominant research approach seems to be qualitative research, even though there are articles using quantitative or mixed methodologies. This might be attributed to the conditions under which researchers work, along with data accessibility factors (Bell, 2001; Cohen et al., 2011). These findings are compatible with the development, introduction and application of the Next Generation Science Standards, which are inter-related to the actual aspects and goals of science teaching and reflect the developments in the concept of scientific literacy (NGSS, 2013; OECD, 2019). As is evident from the above findings, the topics of the journal articles reflect the general trends of research in the fields of pedagogy and science education (Ary et al., 2010; Pring, 2000).

\section{CONCLUSIONS}

The goal of this research was to examine the topics that contemporary researchers in science education focus on. In doing so, it concentrates on research articles published in refereed education journals, since this type of dissemination reflects the topic under investigation accurately (Bywood et al., 2008; Pring, 2000). The ultimate goal of science teaching is the development and achievement of scientific literacy among learners, which has been evolved and developed over the decades. The main axis of this development has been the shift of focus from content knowledge alone to knowledge along with practices, skills and attitudes (Martin et al., 2012; NGSS, 2013; OECD, 2000, 2019). This complex concept entails multiple parameters of scientific knowledge and learning outcomes. These parameters have evolved as different topics that researchers and articles in the field of science teaching have been focusing on. These topics are Teacher Education and Professional Development, Teaching Practices, Learning Concepts, Conceptions and Misconceptions, Curriculum and Policy, Social aspects, Cultural Aspects, Nature of Science, ICT in Science teaching, and Informal Learning of Science. Any research conducted already has examined the topics in journals oriented to science education and has shown that in the previous decades, there was more emphasis on teacher education, teaching practices, misconceptions and ICT (Chang et al., 2009; Chin et al., 2018; Penick \& Yager, 1986). 
The data from this article has been culled from journals that focus generally on the field of education. More specifically, it was examined as to how many articles in these journals addressed science education and in which of the previous topics (Ary et al., 2010; Cohen et al., 2011).

As the findings revealed, firstly, there is a respectable number of articles that address science education, in journals that focus generally on educational research, which shows scholars' fascination with this field (OECD, 2000, 2006, 2019). The lack of comparable or similar findings in previous research makes it impossible to determine whether this number has increased or decreased (Cohen et al., 2011; Pring, 2000). There is strong emphasis on articles that research teaching practices and learning concepts, apart from articles that focus on using ICT in science teaching and curriculum. Topics such as learners' misconceptions, which seemed to be rather frequent in previous decades, were rare in the sample of this research. All these can be attributed. as mentioned earlier, to the development of the concept of scientific literacy and the general trends in the field of science education. This confirms that any development in the field of research has its impact on the topics of the articles published (Martin et al., 2012; NGSS, 2013; OECD, 2000, 2019).

Before generalizing these conclusions, it is important to point out certain limitations of this study. This research examined a specific number of articles from a specific number of issues of specific journals. In the light of the time restrictions and general conditions, it was not possible to examine a larger number. Perhaps, in future, similar research could be carried out involving greater numbers of journals and articles, so that these findings can be developed further (Cohen et al., 2011).

\section{REFERENCES}

Ary, D., Jacobs, L. C., Sorensen, C., \&. Razavieh, A. (2010). Introduction to research in education. Belmont, CA: Wadsworth.

Bell, J. (2005). Doing your research project. A guide for first-time researchers in education, health and social science. 4th Ed. Beckshire: Open University Press.

Best, J., \& Kahn, J. (2006). Research in education. 10th Ed. Boston, USA: Pearson Education.

Bodner, G., \& Elmas, R., (2020). The impact of inquiry-based group-work approaches to instruction on both students and their peer leaders. European Journal of Science and Mathematics Education, 8(1), 51-66. https://doi.org/10.30935/scimath/9546

Bywood, P. T., Terao, H., \& Roche, A. M. (2008). Effective dissemination: An examination of theories and models of change for research dissemination in the AOD field. National Centre for Education and Training on Addiction, Adelaide.

Chang, Y.-H., Chang, C.-Y., \& Tseng, Y.-H. (2009). Trends of Science Education Research: An Automatic Content Analysis. Journal of Science Education and Technology, 19(4), 315-331. https://doi.org/10.1007/s10956-009-9202-2

Cohen, L., Manion, L., \& Morrison, K. (2011). Research methods in education. 7th Ed. London: Routledge.

Dewey, J. (1938). Logic: The theory of inquiry. New York: Holt, Rinehart \& Winston.

Driver, R., Leach, J., Millar, R., \& Scott, P. (1996). Young People's Images of Science. Buckingham: Open University Press. https://doi.org/10.1080/03057268308559904

Gil-Pérez, D. (1996). New trends in science education. International Journal of Science Education, 18(8), 889-901. https://doi.org/10.1080/0950069960180802

Lin, T.-J., Lin, T.-C., Potvin, P., \& Tsai, C.-C. (2018). Research trends in science education from 2013 to 2017 : a systematic content analysis of publications in selected journals. International Journal of Science Education, 41(3), 367-387. https://doi.org/10.1080/09500693.2018.1550274

Martin, M. O., Mullis, I. V. S., Foy, P. \& Stanco, G., (2012). TIMMS 2011 international results in science. Boston: TIMSS \& PIRLS International Study Center. https://timssandpirls.bc.edu/timss2011/downloads/T11_IR_Science_FullBook.pdf (Accessed 29 October, 2020).

McDermott, L. C. (2013). Improving the teaching of science through discipline-based education research: An example from physics. European Journal of Science and Mathematics Education, 1(1), 1-12. https://doi.org/10.30935/scimath/9381

NGSS (2013). Next Generation Science Standards, Science and Engineering Practices in the NGSS. http://www.nextgenscience.org/nextgeneration-science-standards (Accessed 29 October, 2020).

Nyberg, K., Koerber, S., \& Ostehaus, C. (2020). How to measure scientific reasoning in primary school: A comparison of different test modalities. European Journal of Science and Mathematics Education, 8(3), 137-144. https://doi.org/10.30935/scimath/9552

OECD (2000). Measuring Student Knowledge and Skills: The PISA 2000 Assessment of Reading, Mathematical and Scientific Literacy. Paris: PISA, OECD Publishing. https://doi.org/10.1787/9789264181564-en 
OECD (2006). Assessing Scientific, Reading and Mathematical Literacy: A Framework for PISA 2006. Paris: PISA, OECD Publishing. https://doi.org/10.1787/9789264026407-en

OECD (2019). PISA 2018 Results (Volume II): Where All Students Can Succeed, PISA. Paris: PISA, OECD Publishing. https://doi.org/10.1787/b5fd1b8f-en

Penick, J. E., \& Yager, R. E. (1986). Trends in science education: some observations of exemplary programmes in the United States. European Journal of Science Education, 8(1), 1-8. https://doi.org/10.1080/0140528860080101

Pring, R. (2000). Philosophy of Education Research. London: Continuum. 